\title{
Conclusion: Chaos and Culture: Postmodernism(s) and the Denaturing of Experience
}

$\mathrm{W}$ HAT in the present cultural moment has energized chaos as an important concept? Why does it appear as a pivotal concept for us here and now? I conjecture that disorder has become a focal point for contemporary theories because it offers the possibility of escaping from what are increasingly perceived as coercive structures of order. But in privileging disorder, theorists cannot extract themselves from the weight of their disciplinary traditions, even if they want to (and scientists, for the most part, do not want to). Thus there arise complex layerings in which traces of old paradigms are embedded within new, resistances to mastery are enfolded with impulses toward mastery, totalizing moves are made in the service of local knowledge. The convoluted ambiquity that arises from these layerings is the leitmotif of this chapter; it is deeply characteristic of what I shall call cultural postmodernism. For it to come into being, earlier paradigms first had to be understood as constructions rather than statements of fact.

I define cultural postmodernism as the realization that what has always been thought of as the essential, unvarying components of human experience are not natural facts of life but social constructions. ${ }^{1}$ We can think of this as a denaturing process. To denature

'I am grateful to David Porush for suggesting this metaphor to me and for providing valuable background material for this chapter in his book The Soft Machine: Cybernetic Fiction (New York: Methuen, 1985). Daniel Malamud helped me to unravel the complexities of denaturing as a technical process. 
something is to deprive it of its natural qualities. Alcohol is said to be denatured, for example, when its natural chemical composition is altered by additives. Denaturing also carries the technical sense of altering macromolecules by treating them with chemicals or radiation. One of the molecules commonly treated in this way is DNA. Denaturing was an important step in breaking the secret of DNA's structure, for it allowed the double helix to be unwound. The unraveling of DNA's structure led in turn to bioengineering and to the possibility that human genetic material can be reconfigured. The denaturing process, then, is one of the technical developments that helped to constitute cultural postmodernism. It is also a metaphor for postmodernism's deeper implications. When the essential components of human experience are denatured, they are not merely revealed as constructions. The human subject who stands as the putative source of experience is also deconstructed and then reconstructed in ways that fundamentally alter what it means to be human. The postmodern anticipates and implies the posthuman.

The denaturing process proceeded as three waves of related events. Each wave was more or less distinct from the others, but they reinforced each other and at times flowed together. In the first wave language was denatured, in the sense that it was seen not as a mimetic representation of the world of objects but as a sign system generating significance internally through series of relational differences. In the second wave context was denatured when information technology severed the relationship between text and context by making it possible to embed any text in a context arbitrarily far removed from its point of origin. In the third wave time was denatured when it ceased to be seen as a given of human existence and became a construct that could be conceptualized in different ways. With language, context, and time all denatured, the next wave, as I have intimated, is the denaturing of the buman. While this fourth wave has yet to crest, it is undeniably building in force and scope.

\section{The Denaturing of Language}

Of all the components of cultural postmodernism, the denaturing of language is the most extensively documented within the literary community, so I shall spend the least time on it. It resulted from the 
confluence of two currents of thought. One was expressed by attempts in the early years of this century to eliminate ambiguity and self-reference from formal systems. These attempts were sufficiently widespread to constitute an important part of the period's intellectual landscape. In mathematics, Whitehead and Russell led the way with the Principia Mathematica; in language theory, logical positivism held center stage with its program to purge discourse of imprecise utterance; and in physics, Einstein developed the special theory of relativity to provide an overarching framework within which observations from different inertial systems could be reconciled. These projects had in common the belief that it was possible to create a metalanguage that would not be contaminated by the assumptions of the object language. One by one, they were either discredited or reinterpreted to accommodate the realization that, as Niels Bohr observed, "we are suspended in language."

The attempt to axiomatize mathematics led in I93 I to Gödel's theorem, which demonstrated that any formal system complicated enough for arithmetic must be either incompletely described or contradictory. Logical positivism, already in trouble by World War II, was dealt a death blow by such philosophers of science as T. S. Kuhn, N. R. Hanson, and P. Feyerabend, who argued convincingly that observational statements are always theory-laden. The special theory of relativity lost its epistemological clarity when it was combined with quantum mechanics to form quantum field theory. By mid-century, all three had been played out or had undergone substantial modification.

If we think of these projects as attempts to ground representation in a noncontingent metadiscourse, surely it is significant that the most important work on them appeared before World War I. Einstein published his papers on the special theory of relativity in 1905 and the general theory in I9I6; the Principia Mathematica volumes appeared from r9ıo to I9I3; and logical positivism had its heyday in the closing decades of the nineteenth century. After World War I, when the rhetoric of glorious patriotism sounded very empty, it must have been much more difficult to think that language could have an absolute ground of meaning. Out of attempts to conceptualize symbols systems as unified fields of representation arose the real-

${ }^{2}$ For a fuller treatment of these developments, see Hayles, ${ }_{9} 84$. 
ization that positing an all-inclusive field meant there was no vantage point outside the field from which to speak. Consequently, every utterance or representation already assumed what it purported to describe.

More or less independently, a second current contributing to the denaturing of language developed out of Saussurean linguistics. It is now an oft-told story that Saussure, by defining la langue as a sign system generating significance through differences between language elements, imagined language as an interactive field in which the meaning of any one element depends upon the interactions present in the field as a whole. Indeed, Saussure went so far as to assert that if any one word were removed-say, "pig" - the field would be altered, and consequently the significance of all remaining words would change. (To an lowan, the assertion that removing "pig" would change the entire language is self-evident.)

Saussure's interactive view of language has certain affinities with the events sketched above, particularly with the development of quantum mechanics and relativity theory. There are also important differences. Whereas quantum field theory led to a very specific and limited sense of the uncertainty imposed by observing or speaking from within the field (defined by Planck's constant in the uncertainty principle), Saussurean linguistics was appropriated to support the deconstructive view that all utterance is ungrounded and indeterminate. These differences notwithstanding, quantum field theory has often been held up as validating the view that language is inherently self-referential and ungrounded. In this sense the two currents flowed into a single stream and constituted the first wave of cultural postmodernism, the denaturing of language.

By saying language was denatured, I mean to indicate a self-conscious attitude toward language in which signification is regarded as always already problematic. The sense that language is constantly unraveling, even as one weaves it into a design; that any utterance can be deconstructed to show that it already presupposes what it would say and hence has no prior ground on which to rest; that all texts are penetrated by infinite numbers of intertexts so that contextual horizons are always constructions rather than givens; in short, that signification is a construction rather than a natural result of speaking or writing-all this was implied by the denaturing process 
as it applies to language. Denatured language is language regarded as ground painted under our feet while we hang suspended in a void. We cannot dispense with the illusion of ground, because we need a place from which to speak. But it is bracketed by our knowledge that it is only a painting, not natural ground.

\section{The Denaturing of Context}

The denaturing of context crested after the denaturing of language, although both continue to be important components of cultural postmodernism. Just as World War I marked the end of the most ambitious and successful attempts to find a noncontingent ground for representation, World War II marked the point at which these matters ceased to be of merely theoretical concern and entered the mainstream of the culture through information technology. By World War II, transportation and aircraft had progressed sufficiently so that rapid troop movments were possible, which in turn made accurate and timely information as critical to the war effort as weapons and soldiers. World War II made information real.

The years immediately following the war saw an explosion of interest in information theory and technology. Research on information theory and systems was directly linked with the war effort. The cracking of the Enigma code by Alan Turing was crucial to Allied strategy in the last phases of the war; Turing was also responsible for proving certain theorems about information which greatly advanced the nascent art of computer technology. A similar connection exists in the work of Norbert Wiener. Although Wiener's contribution to the war effort doubtless loomed larger in his mind than in anyone else's, it was nevertheless his attempt to construct a guidance system for anti-aircraft weapons that directed the attention of theorists to information as a way to deal with intrinsically uncertain situations. Wiener, like Turing, was quick to see applications to postwar technology and promoted them in his book on cybernetics published a few years after the war.

Further evidence for the catalyzing effect of the war on information theory is Donald MacKay's account of how he began to formulate his ideas about information. "Towards the end of the Second 
World War in the Admiralty's radar establishment," MacKay writes, "I found myself trying to follow the behavior of electrical impulses over extremely short intervals" (I969:I). Mackay, an important early researcher in the field, recalls that the idea of information was very much in the air during and immediately following the war. Additional indications of the importance of World War II are the dates of the first dramatic breakthroughs in information theory. Shannon's two seminal papers were published in 1948 , Wiener's book on cybernetics the same year, Brillouin's analysis of information and entropy in $195 \mathrm{r}$.

Shannon's definition of information as a statistical measure of uncertainty had important implications for the relation of text to context. As long as meaning and information are connected, the information value of a message remains bound to its context. Consider, for example, how the meaning of "down" changes when I say it to my dog and when my stockbroker says it to me in response to a query about the market. If information is tied to meaning, its value is subject to change every time a message is embedded in a new context. Shannon, an electrical engineer working for Bell Laboratories, knew that information could not be used as the basis for a new technology unless it could be reliably quantified. From his point of view, an entity whose value changed whenever it was transported to a new place was a nightmare. He cut through the complexities of context dependence by the simple expedient of declaring that information had nothing to do with meaning. By implication, informational texts were also cut loose from their dependence on contexts.

At this point in my story, the first and second waves come together. Shannon, having cut information loose from its moorings in

${ }^{3}$ Shannon, r948; Brillouin, I95I; Norbert Wiener, Cybernetics; or Control and Communication in the Animal and the Machine (Cambridge: MIT Press, 1948). The war may have left its stamp on information theory in other ways as well. We saw in chap. 2 that Shannon defined information as a measure of uncertainty over the strenuous objections of other theorists such as Brillouin. Was it the war that made the association of information with uncertainty seem compelling to Shannon and to later theorists who adopted his convention? Did the anxiety of trying to interpret uncertain wartime information facilitate the disjunction of information from meaning? Mary Lou Emery, in a private communication, has observed that these questions are importantly related to the way gender formations were reconstituted in the aftermath of World War II. 
referentiality, was forced to define it internally through relational differences with other elements in the appropriate symbol set. Thus Shannon's theory of information is conceptually analogous to Saussure's theory of la langue, as well as to certain aspects of quantum field theory. But Shannon's move came at a decisively different point in time, when cultural conditions were ripe for the rapid development of information technology. His move was important less because it was a theoretical innovation than because it initiated a feedback loop linking theory, culture, and technology.

The aspect of this loop that I shall concentrate on, and that constitutes the second wave of postmodernism, is the denaturing of context. Initially messages were separated from contexts because such a move was necessary to make information quantifiable. Once this assumption was used to formulate a theory of information, information technology developed very rapidly. And once this technology was in place, the disjunction between message and context which began as a theoretical premise became a cultural condition.

Among the first indications that separating messages from their contexts could have dramatic effects were the weapons-guidance systems that an improved information technology made possible. Primo Levi (1985), in his account of Jewish partisans fighting against the Germans in World War II, vividly recalls what it felt like for the weapons operator to be separated from the context in which the weapons were used.

I was in the artillery, you know. It's not like having a rifle. You set up the piece, you aim, you fire, and you can't see a thing. ... Who knows how many men have died at my hand? Maybe a thousand, maybe not even one. Your orders come by field telephone or radio, through earphones: left three, drop one, you obey, and that's the end of it. It's like bomber planes; or when you pour acid into an anthill to kill the ants: a hundred thousand ants die, and you don't feel anything, you aren't even aware of it. [1985:IIO-III).

Since World War II, weapons-guidance systems have of course become much more sopisticated, transforming the psychology of modern warfare. The awareness that our entire social context can be annihilated by weapons that we will not even see is no doubt one reason why contexts in general seem to us precarious, capable of instantaneous mutation or extinction. 
Another area in which the separation of text from context has had dramatic effects is biogenetics. Although microbiologists would probably not say it this way, organisms are in effect viewed as informational texts that can be opened to a literal embodiment of intertextuality by a variety of gene-splicing techniques. Such techniques point to the deconstruction of the body as text, rendering problematic distinctions between originary texts and clones. Similar deconstructions are occurring with traditional ideas of parenthood as new birth technologies make it possible to withdraw eggs from a woman, freeze them for an indefinite period, fertilize them in vitro, and place them in the uterus of the same woman at a later time or in another woman. When the genetic text of the unborn child can be embedded in a biological site far removed from its origin, the intimate connection between child and womb which once provided a natural context for gestation has been denatured.

Test-tube babies are, of course, extraordinary instances that directly touch the lives of only a few people. But denatured contexts are not extraordinary. Far from being confined to the kind of events that make newspaper headlines, they are extremely common. Take MTV as an example. Turn it on. What do you see? Perhaps demonlike creatures dancing; then a cut to cows grazing in a meadow, in the midst of which a singer with blue hair suddenly appears; then another cut to cars engulfed in flames. In such videos, the images and medium collaborate to create a technological demonstration that any text can be embedded in any context. What are these videos telling us, if not that the disappearance of a stable, universal context is the context for postmodern culture?

G. W. S. Trow (1978), following a similar line of thought, has argued that contemporary Americans live "within the context of no context." According to Trow, context as such has disappeared because our lives are split between an enormous grid of two hundred million people and the intimate family circle gathered around the TV set. With very little in between, especially for the growing percentage of the population who live in large urban centers, these two very different communities of discourse try to pretend that they share the same context. Consequently, context becomes a construction rather than a natural result of shared activities.

One of Trow's best examples is the TV talk show. Talk shows 
thrive on the audience's expectation that something indecorous is about to be said or done. But impropriety is possible only when a social context exists which can be violated. Since no shared context in fact exists, the host must create the illusion of one. (In rare cases in which the context is taken to be the studio, as on Saturday Night Live, the violations are of another order.) To make the double move of creating and violating context, the host arranges the guests so that they appear to form an intimate circle of friends. Each new guest then arrives on the scene as an intruder for whom space must be made. The host also tries to make the audience feel that it is part of this intimate social group, as by direct address. But the constant splicing into other contexts through commercials and station breaks reminds us that context is always already a construction, created for specific purposes and dispelled as soon as these purposes are achieved. ${ }^{4}$

Trow, an environmental and short story writer who publishes elegantly ironic pieces in The New Yorker, is not concerned with the academic controversies that swirl around postmodernism. Nevertheless, his observations about context illuminate much that has been written on postmodern aesthetics. Most theorists writing on postmodernism agree, for example, that contemporary architecture is an important site for displays of postmodernism. Why? In Trow's terms, because it provides an arena for exploring the problematics of decontextualization. Robert Venturi, in Learning from Las Vegas (1972), points out that the assumed context for the great gambling casinos and hotels is not the land on which they are built but the moving automobile from which they are seen. Similarly, Kenneth Frampton argues for "critical regionalism" because he is all too well aware that traditional connections between structures and their environmental contexts are up for grabs (Foster, 1983:16-30). If they were assumed, it would be redundant to argue that buildings should relate to their sites.

As contexts are increasingly seen as constructions rather than

${ }^{4}$ Perhaps the most blatant examples of created contexts are so-called media events, which exist only so that the media can film them. Trow considers such events cons. The way to recognize a con, he says, is to ask yourself, "Would this be happening if I were not here to see it?" If the answer is no, then you are the context for the event, and any other context is an illusion created to manipulate your responses. 


\section{Chaos Bound}

givens, who controls which context for what purpose becomes an important question. Consider the term "context control," which entered the vernacular as a euphemism favored by government spokesmen. It implies that if one can control the context in which damaging information is released, one has a much better chance of controlling the way the information will be interpreted. It goes without saying that in these instances context is seen as a construction to be manipulated rather than a preexisting condition. Another example is the "disinformation" that government officials have acknowledged giving out to the domestic press as well as to foreign governments. Only in a (created?) context of national security is it plausible to distinguish between "disinformation" and lies.

Since its introduction by professional image makers, context control has become an increasingly widespread concern. It is a central issue in situations where computers are used to reconstruct incomplete or missing information. Satellite transmissions, for example, are customarily presented to the public, the media, and governmental decision makers in "image-enchanced" form: the original informational text has been fed into a computer and reconstituted into a more coherent image designed to enhance its salient features. The enhancement process is designed as an information-preserving transformation only for certain variables. Other variables are necessarily changed, since their alteration is what allows the image to be enhanced for the context of interest. The process blurs the boundaries between text and context, for an assumed context has already changed the image before we see it. In these instances controlling context is literally equivalent to controlling interpretation. The technological sophistication and flexibility of modern context control make it different in kind, as well as in degree, from the forms practiced in earlier eras. The Renaissance courtier who waited until his sovereign had dined before breaking bad news was practicing context control in rudimentary form. But only with the advent of modern information technology has context control ceased to be an occasional phenomenon and become a sophisticated set of strategies endemic in postmodern society.

So fluid and changeable are the contexts of contemporary life that new kinds of units, context-plus-text, are emerging. Max Headroom, for example, lived permanently within the context of the TV 
screen. Because they were inseparably fused, the framing screen and image provided the illusion of a stabilized context. But this new unit could in turn be embedded in other contexts, usually other TV sets, setting up a self-reflexive play between Max's TV screen and the TV screen framing it. The visual reflection of Max's screen in the surrounding screen is equivalent to the TV talk show's ploy of simultaneously creating and violating context. The stability that one screen bestows the other takes away. What better way to depict what it means to live within the context of no context?

\section{From Denatured Contexts to Reconfigured Spaces}

So thoroughly has context been denatured that it may be only a matter of time before the distinction between text and context collapses altogether. As early as the 1940s and I950s, Borges was playing with this idea in such stories as "The Don Quixote of Pierre Menard" and "Tlön, Uqbar, Orbis Tertius" (I98I). More recently, writers and theorists speak of contexts that cannot be characterized in conventional terms, as if their collapse had catapulted us into a new kind of space. In the science fiction novel Neuromancer (I 984), for example, William Gibson imagines a world in which computer cowboys jack into microcomputers interfaced directly with their neural systems. When a cowboy fuses with a computer in this fashion, he enters cyberspace, a theater of operations beyond conventional time and space. In this new kind of space, intelligences (artificial and otherwise) sense each other's presences in ways unique to the medium. Cyberspace is a world unto itself, touching the conventional world at every point but remaining entirely distinct from it. The protagonist, a cowboy who has been altered by subtle chemical torture so that he can no longer enter cyberspace, considers life hardly worth living if he has to remain forever trapped in the ordinary dimensions of spacetime.

Gibson's vision has much in common with Baudrillard's theory of simulacra. Although Baudrillard (I98I, I983) tends to be more openly ironic about the social and technological forces that have caused late capitalism to "implode" and create a new kind of space, his concept of the hyper-real is like Gibson's cyberspace in that it 
images a space that touches the conventional world at every point but that has nevertheless undergone a radical transformation. As we saw in chapter 9, the hyper-real comes into existence when copies refer no longer to originals but to other copies; or more precisely, when it is impossible to distinguish any longer between a copy and an original. Like cyberspace, the hyper-real presupposes a radical erosion of context, for the sense that something is an original depends upon its association with a unique context. Consider: a London bridge is dismantled and transported stone by stone to the Arizona desert, where it is reassembled. The bridge is physically the same (within limits imposed by the plasticity of the material); but is it an original or a copy? The undecidability of the question illustrates how deeply the sense that something is a simulacrum is bound up with the loss of a stable context.

Both Gibson and Baudrillard are fascinated by the possibility that cryogenics may extend these kinds of questions to human beings. Is a Walt Disney frozen and brought back to life in the year 2050 the same man who created Snow White, or a copy? In Neuromancer, the corrupt and powerful clan of Tessier-Ashpool has for generations practiced cryogenics, so that its members have virtually all become simulacra (as their replicated names and numbers indicate). The prospect that human beings can become simulacra suggests that a new social context is emerging which will change not only what it means to be in the world but what it means to be human. Within this context-of-no-context, the postmodern shades into the posthuman.

Neuromancer is full of characters who have implanted into their bodies various kind of cybernetic devices, from the mirrored electronic eyes and retractable razor claws of the heroine to the shark skin and teeth grafted onto the face of a new-age punker. A common implant is a socket behind the ear into which computer chips can be plugged, creating a direct interface between human and computer memory. If one is going to an art auction, for example, one plugs in the appropriate chip and becomes an instant art expert. Such fusions of human organism and cybernetic mechanisms may seem farfetched. But in fact cyborgs (a term coined from cybernetic organism) already exist and are not particularly uncommon. About 10 
percent of the U.S. population are cyborgs, including people who have electronic pacemakers, artificial joints, prosthetic limbs, and artificial skin.

As important as the increasing numbers of actual cyborgs are the ways in which we envision ourselves as parts of cybernetic circuits, even when our biological boundaries are intact. For example, Gibson in an interview (Greenland, 1986) described a teenager playing a video game as "a feedback loop of particles: the photons are coming out of the screen and going into the guy's eyes, and the neurons are moving through his body, and the electrons are moving through the computer." Physically intact, the player is nevertheless already a cyborg, for he is joined to the computer by a continuous interplay between his neural system and the computer's circuitry. In this view, to have nondetachable cybernetic implants is simply to reify the detachable connections that already bind humans to computers in thousands of video arcades and computer centers across the country. "I had a hunch from talking to people about computers," Gibson continues, "that everyone seemed to feel at some level, without really ever saying it, that there was space behind the screen. I just took that and ran with it as far as I could" (p. 7).

As the context-of-no-context transmutes into a new kind of space, the connections between denatured space and the new geometries become more apparent. In his influential article "Postmodernism, or The Cultural Logic of Late Capitalism" (I984), Fredric Jameson takes as an example of reconfigured space the Bonaventure Hotel in Los Angeles. ${ }^{5}$ He points out that in contrast to the opulent entrances of older hotels, the Bonaventure's doors are obscure. Moreover, they open onto obscure spaces. He intimates that the Bonaventure in effect disguises its entrances because it "aspires to being a total space, a complete world, a kind of miniature city. . . . It does not wish to be a part of the city, but rather its equivalent and its replacement or substitute" (p. $8 \mathrm{I}$ ). Its public spaces are organized to make conventional reference points inapplicable. The lobby is surrounded by four identical towers, for example, so that the most prominent architec-

'The correct name of the hotel is the Bonaventura. For consistency, however, I will follow Jameson's usage in my discussion. 
tural features are useless for spatial orientation. Streamers hanging over the four-story lobby make it impossible to estimate the lobby's volume and create a sense of a complex noncontinuous space that defeats usual lines of perspective. So far Jameson's description of the Bonaventure could, virtually without revision, be taken as an accurate description of cyberspace as Gibson represents it in Neuromancer.

When one reads about the feature that Jameson sees as confirming his diagnosis, the resemblance turns uncanny. The culminating sign of a reconfigured space, Jameson argues, is the Bonaventure's "great reflective glass skin," which he sees as analogous to "those reflector sunglasses which make it impossible for your interlocutor to see your own eyes" (p. 82). The parallel feature of Neuromancer is the heroine's mirror shades, which we only gradually realize are permanent cybernetic implants. In commenting on them, Brooks Landon has suggested that they represent a "polished chrome future in which reflection-surface-becomes the new reality," a future in which "electronic images, holographs, clones, cyborgs, and hallucinations intermingle ... where almost everything reflects, replicates, or imitates something else" (I987:31). As Landon points out, and as the Bonaventure demonstrates, they are also a distinctive architectural feature of multinational corporate headquarters.

For Jameson, postmodernism is not a style but a "cultural dominant," emerging from capitalistic commodification carried to the extreme. As information replaces industrial production as the basis for the economy, capitalism does not disappear. Rather it enters its purest form, for now there is a quantifiable medium of exchange to which everything can be reduced, even human beings. Consequently, such high-tech buildings as the Bonaventure are not signifiers that point to technology as the signified. Instead, technology itself is a signifier, pointing to a mass of interconnected information networks of such enormous complexity that the human mind can no longer comprehend them. According to Jameson, that is why we structure our buildings and our narratives to image spaces so complex they elude human comprehension. Our technology is simply another image we make to body forth our sense of the global networks that control our lives, but that are so far beyond our powers of perception that we cannot even see them, much less control them. 
What happens to time in postmodernism is very different from what happens to space. Whereas space detaches itself from mundane reality and forms a richly configured realm of its own, time sinks into the media experience of constructed, repetitious packages and becomes a series of disconnected intervals. As with much else, Borges anticipated this development in his essay "New Refutation of Time" (1964), which observes that human identity depends on memory and memory depends on seeing time as a continuous orderly progression. If time is cut loose from the idea of sequence, Borges suggests, every man who reads Shakespeare becomes, for that moment, Shakespeare. The cutting loose of time from sequence, and consequently from human identity, constitutes the third wave of postmodernism. Time still exists in cultural postmodernism, but it no longer functions as a continuum along which human action can meaningfully be plotted.

In Being and Time (1962), Heidegger used the finitude of human being as a fixed point from which to establish the possibility of an authentic life. Because we are finite, because there is an end point to our time as personally lived, it is possible for us to experience the dread that alone leads us to understand the nature of our condition. Derrida later argued (1976), in part on the basis of his reading of Heidegger, that there is no point of origin, that language and context are "always already" denatured. But still there was an end point to human being, and it provided the possibility of a stablized, if contingent, meaning. Since the I960s, the consensus that there is a fixed end point has been eroded by our growing sense that the future is already used up before it arrives. Thus human being is left freefloating between an unimaginable origin displaced beyond itself before the beginning of time and an indeterminate end shifted into the present or even into the past.

How did we come to believe that the future, like the past, has already happened? Such terms as "postmodern" and "postapocalyptic" provide clues. The rhythm of our century seemed predictable. World War I at the second decade; World War II at the fourth decade; World War III at the sixth decade, during which the world as we know it comes to an end. But somehow it did not happen when 
it was supposed to. By the ninth decade, we cannot help suspecting that maybe it happened after all and we failed to notice. Consequently time splits into a false future in which we all live and a true future that by virtue of being true does not have us in it. Variations of this scenario have persisted in our literature and film for years. As early as 1962, Philip K. Dick was writing it in The Man in the High Castle; Nabokov pursued a variation in Ada or Ardor: A Family Chronicle (x969); Walker Percy played with it in Love in the Ruins (197 1). More recently, such films as Back to the Future, Brazil, Terminator, and Peggy Sue Got Married also toy with the idea.

Reinforcing the sense that the future has been used up before it arrives is the acceleration that Alvin Toffler, in a phrase that now seems antiquated, termed future shock. Pop culture changes so quickly that to be current one must be futuristic, for if one is merely up to date one is already out of fashion. Technology seems to change at least as fast, especially information technology. For example, it is estimated that the limits of silicon technology will be reached in about a decade. Research is already being conducted on materials that have the potential to use photons rather than electrons to carry information (gallium arsenide is currently the material of choice). With photonic materials messages travel at the speed of light; consequently transmission times will be even shorter than they now are. In a review of information technology materials for Scientific American, John S. Mayo significantly does not conclude that limits inherent in photonic materials will finally act as a brake on development. Rather, he foresees that humans will become increasingly peripheral to information processing. "The higher the functionality of a system is," Mayo writes, "the more important its software component. To reach the highest levels of functionality, [we must] build systems that are self-directing and independent of intelligent human beings [emphasis added].'

Part of our sense that time has flattened out derives from uncertainty about where we as human beings fit into our own future scenarios. A Saturday morning spent watching cartoons will convince the skeptical how prevalent are our images of ourselves as mere cores on which to encrust cybernetic mechanisms (a theme devel-

"John S. Mayo, "Materials for Information and Communiction," Scientific American 255 (October 1986):65. 
oped at length in Robocop).? These images imply something more than the usual doubt among the young that history in general and the older generation in particular have anything useful to teach them. They point to a feeling that time itself has ceased to be a useful concept around which to organize experience. If we may or may not be simulacra displaced into the present from previous contexts; if we cannot envision ourselves in the future without imagining that it has undergone a phase change into a different kind of space; if the future is already used up before we can achieve such a projection, problematic as it may be-if all this is true, then time is not just denatured. It is obsolete.

The paradoxical notion that time could be obsolete has been hinted for some time now among theorists interested in postmodern aesthetics. The claim usually is phrased more gently (for obvious reasons, given the paradoxes it engenders), but it is nonetheless widespread. As mentioned earlier, Michel Serres (I982a) sees the temporal aesthetic of nineteenth-century realism giving way to a spatial aesthetic focusing on deformations, local turbulence, and continuous but nondifferentiable curves. Fredric Jameson (r984) has argued that, along with a reconfigured space, a weakening of a sense of historicity is one of the constituent features of postmodernism. Analyzing postmodernism, then, amounts to writing the history of no history. In an important sense, to write the history of postmodernism is to indulge in anachronism.

In this anachronistic history, a dichotomy emerges between those who write about postmodernism and those who live it. Such theorists as Jameson, Andreas Huyssen, Jürgen Habermas, Jean-François Lyotard, Craig Owens, and Hal Foster are concerned to locate postmodernism as part of a historical sequence that began with modernism. ${ }^{8}$ They vary in their estimations of how successful, and even

'The prevalence of cybernetic imagery in children's toys and television shows is documented by Gabriele Schwab, "Cyborgs, Postmodern Phantasms of Body and Mind," Discourse 9 (Spring-Summer I987): 64-84.

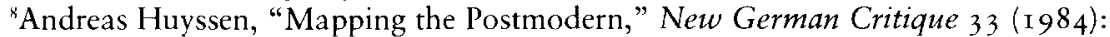
5-52; Jürgen Habermas, "Modernity versus Postmodernity," New German Critique 22 (I 98 I): 3-I4, and "Modernity-An Incomplete Project," in Foster, I983:3-I 5; Craig Owens, "The Allegorical Impulse: Toward a Theory of Postmodernism, Part 2," October I 3 (1980): 59-80; Hal Foster, "Postmodernism: A Preface," in Foster, 1 983 :ix-xvi. 
what, modernism was; they disagree about whether it is continued or refuted by postmodernism. Whatever their stance, however, they concur that postmodernism has a history, and thus that it has roots in such intellectual issues as the self-referentiality of symbol systems, the Kantian sublime, the cultural logic of late capitalism, and so forth.

The case is very different for those who live postmodernism. For them, the denaturing of time means that they have no history. To live postmodernism is to live as schizophrenics are said to do, in a world of disconnected present moments that jostle one another but never form a continuous (much less logical) progression. The prior experiences of older people act as anchors that keep them from fully entering the postmodern stream of spliced contexts and discontinuous time. Young people, lacking these anchors and immersed in $\mathrm{TV}$, are in a better position to know from direct experience what it is to have no sense of history, to live in a world of simulacra, to see

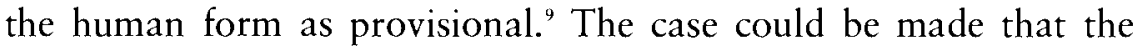
people in this country who know the most about how postmodernism feels (as distinct from how to envision or analyze it) are all under the age of sixteen.

\section{Denaturing the Human}

Faced with the choice of giving way to the postmodern current or trying to resist it, many adults experience ambivalence. They are uneasy with good reason, for the logic of postmodernism seems inevitably to lead to a fourth wave: the denaturing of the human. Donna Haraway's "Manifesto for Cyborgs" (1985) explores the complexities and nuances of this fourth wave. Haraway points out that information technologies are bringing about far-reaching changes in the way boundaries are conceived and constituted. "Any objects or persons," Haraway writes, "can be reasonably thought of in terms of disassembly and reassembly; no 'natural' architectures constrain system design. The financial districts in all the world's cities, as well

${ }^{9}$ The effect of television has of course extensive implications. Some of them are explored in Todd Gitlin, ed., Watching Television (New York: Random House, I987). 
as the export-processing and free-trade zones, proclaim this elementary fact of 'late capitalism'" (p. 8I ). Haraway argues that information technology has made it possible for us to think of entities (including human beings) as conglomerations that can be taken apart, combined with new elements, and put together again in ways that violate traditional boundaries.

From one perspective this violation is liberating, for it allows historically oppressive constructs to be deconstructed and replaced by new kinds of entities more open to the expression of difference. The problem, of course, is that these new constructs may also be oppressive, albeit in different ways. For example, much feminist thought and writing since the I940s has been directed toward deconstructing the idea of "man" as a norm by which human experience can be judged. To achieve this goal, another construction has been erected, "woman." Yet as it has been defined in the writings of white, affluent, heterosexual, Western women, this construct has tended to exclude the experiences of black women, Third World women, poor women, lesbian women, and so on. The problem is another form of the local/global problematic, for the new globalized constructs replicate the old in the sense that they too repress local variations in what they purport to describe.

How to create the global forms necessary for effective collective action without repressing difference? Following Chela Sandoval, Haraway suggests that it may be possible to "construct a postmodernist identity out of otherness and difference" through "oppositional consciousness" (p. 73). The idea derives from Sandoval's observation that there are no accepted criteria for determining who qualifies as a woman of color. As a group, women have historically been defined negatively, as not-man. People of color have similarly been defined as not-white. Formed by a double negation, women of color have no positive identity. To Sandoval and Haraway this is a great strength, for it opens the possibility of an identity that operates through negativity rather than positivity. Like Jameson and Gibson, they sense the arrival of a new kind of space. But unlike Jameson and Gibson, they are concerned not to define this space, to leave it unconstructed. This of course is self-contradictory, for if the space is unarticulated and unconstructed, how could they write about it and how could we know it exists? The alternative is to fill it with constructions formed by a new kind of dynamic. 


\section{Cyborgs as Denatured Humans}

The sign Haraway erects to preside over her new kind of space is the cyborg. Essential to her vision of the cyborg as a liberating feminist construct is its violation of traditional boundaries. According to Haraway, at least three distinct oppositions are undone by the cyborg: human/animal ("Far from signaling a walling off of people from other living beings, cyborgs signal disturbingly and pleasurably tight coupling," p. 68); human/machine ("Our machines are disturbingly lively, and we ourselves frighteningly inert," p. 69); and physi$\mathrm{cal} /$ nonphysical ("Our best machines are made of sunshine; they are all light and clean because they are nothing but signals, electromagnetic waves, a section of a spectrum. . . People are nowhere near so fluid, being both material and opaque. Cyborgs are ether, quintessence," p. 70). The quotations illustrate Haraway's ironic tone as well as her argument. Indeed, her argument could hardly be made without this tone. Irony usually functions to force us to recognize the gap between the ideal and the actual. In Haraway, the ironic tone is exaggerated until the disparity between ideality and actuality becomes, as Samuel Johnson said of Cymbeline, a fault too gross for detection.

The tone flaunts what Haraway could scarcely conceal if she tried: that the cyborg, as an actuality, is deeply bound up with what Haraway calls the "informatics of domination." The hope that the cyborg can keep the unconstructed space of postmodernism from being filled with newly oppressive constructions is just that-a hope. The reality is that the cyborg has already been appropriated by multinational corporations as they proceed to implement more de-skilling of human labor, more interlocking of data networks, more development of space weapons, and more uncontrollable defense systems.

The point I wish to underscore here is not Haraway's ironic claim that the cyborg can be liberating but her vision of the postmodern as the posthuman. The cyborg is the specific instance for which the denaturing process is the general case. Like the cyborg, denaturing opens up the possibility of unconstructed spaces (although "space" is too narrow a term for what I mean here, since space itself is reconfigured in the postmodern dialectic). And like the cyborg, the 
denaturing process arouses intense ambivalence, especially as it spreads to envelop the human. Language, context, and time are essential components of human experience. However, the human is a construction logically prior to all three, for it defines the grounds of experience itself. If denaturing the human can sweep away more of the detritus of the past than any of the other postmodern deconstructions, it can also remove taboos and safeguards that are stays, however fragile, against the destruction of the human race. What will happen to the movement for human rights when the human is regarded as a construction like any other? Such concerns illustrate why, at the heart of virtually all postmodernisms, one finds a divided impulse.

\section{Looping from Cultural Postmodernism to Theoretical Postmodernisms}

I turn now from talk of postmodernism as a movement determined (and overdetermined) by multiple currents within the culture to discuss specific theories that are postmodern in some sense. With this turn the self-reflexive nature of my argument becomes explicit, for postmodern theories are themselves part of the cultural matrix that $I$ have described as engendering them. Depicting cultural postmodernism as a linear chain of events tends to obscure the complex feedback loops that connect theories to new technologies and social formations, and technologies and social formations to new theories. Narrative linearity, in other words, is fundamentally at odds both with postmodern theories and with the recursiveness of the theorytechnology-social-matrix loop. I shall return to this point near the end of the chapter, when I speculate about the relation of cultural postmodernism to narrative structures in general and to my narrative in particular.

Let me begin the present section (which is actually not a new discussion but another recursive loop through the same discussion) by stating my primary premise. Issues become energized in theories because they are replicated from and reproduced in the social. In the case of theoretical postmodernisms, this means that at least one of the four constituent waves of postmodernism as a cultural dominant 
is involved in a feedback loop with the theory. Usually theories that are perceived as postmodern are in a loop through two or more components of cultural postmodernism. Deconstruction, for example, loops recursively between denatured language and denatured context. The new historicism locates itself at the looping of denatured context with denatured time. Jameson's theory of postmodernism, perhaps the single most influential work on the subject to date, is a triple looping through denatured language, context, and time. Haraway identifies the denatured human through the medium of denatured language; and so forth.

To understand how a specific postmodern theory engages in a feedback loop with postmodernism as a cultural dominant, consider the new historicism as a case in point. Edward Pechter has pointed out that the new historicists (in particular Stephen Greenblatt, Alan Sinfield, Jonathan Dollimore, and the early Foucault) all tend to tell the same story. It is the story of how, as Greenblatt puts it, "in all my text and documents, there were, so far as I could tell, no moments of pure, unfettered subjectivity; indeed, the human subject itself began to seem remarkably unfree, the ideological product of the relations of power in a particular society" (quoted in Pechter, 1987:300). Pechter convincingly demonstrates that underlying this story is a "conception of the text as threat, a hostile otherness designed to dominate the reader." Why, he asks, should texts be conceived in this way?

This is the right question to ask. Unfortunately, Pechter does not answer it (presumably because he has another agenda to follow, which is to deny that "human activity is essentially determined by the will to power," p. 30I). Before he goes off on this tack, however, he remarks that the new historicist view of texts replicates the "antagonistic power relations at the center of the new-historicist thematics" (p. 300). Granted that the thematics of new historicism replicates its view of texts, what in the present cultural moment makes the story of disempowerment seem compelling?

My answer is that the new historicism is one site within the culture at which the ambivalence characteristic of postmodernism is being played out. The potential liberation that the denaturing process promises is realized in the critic's feeling that she has penetrated the text's defenses and exposed the underlying ideology at work. 
The uneasiness to which the denaturing process gives rise is expressed in the kind of stories that are told-stories in which, as Pechter elegantly puts it, "we are only what we are constituted to be by the power relations that govern, anonymously and without human face, even the governors" (p. 300).

The irony is that the more the liberating play of the intellect works on its material, the more power relations are exposed, and consequently the more helpless the subject is made to feel. One could imagine a feedback loop in which the critic writes in order to feel empowered; but the result of her writing is to identify her as a deconstructed subject whose "self" is only the inscription of anonymous forces. Realizing this, she returns to her writing, for now she needs more desperately than ever the feeling of empowerment that comes from writing. But her writing only tells the same story in other ways, and the only relief from it is to write some more. . . Of course this particular feedback loop probably never develops in the simplified way I have suggested. Intervening are all sorts of other factors, such as the fame and recognition that becoming a successful new historicist brings with it. But the idealized scenario helps to explain how feedback loops develop between the act of theorizing and the thematics of a theory, as well as between postmodernism as a cultural dominant and a specific theory that reinforces and reenacts its concerns. No wonder that a writer such as de Man, who positions himself in opposition to mastery, can seem so masterful. The recursiveness of the culture-theory-technology loop makes this kind of ambiguity all but unavoidable.

How do these loops activate suspicion of global theories, and correlatively, make local knowledge seem so important? The contemporary emphasis on local knowledge is reinforced by the social dialectic Trow addressed when he observed that American life is split between a grid of millions and the circle around the TV set. If there were some way to move between these scales, to coordinate the global and local, then context could be renaturalized. For us at this moment, reinscribing local knowledge in contemporary theories is an important project because it is an attempt to mediate between the denatured contexts of cultural postmodernism. Conversely, globalizing theories seem pernicious because they assume that a single, unified context still exists. When denatured contexts are all around us, 
we can no longer believe in the innocence of this assumption. But even the project of recontextualizing comes under suspicion when we realize that our constructions grow out of our culture and that our culture is comprised of our constructions, for then it is no longer possible to separate unambiguously the project of reinscribing local knowledge from a globalizing imperative.

\section{Locating the New Scientific Theories in the Postmodern Loop}

As we saw in chapter 8, Lyotard in The Postmodern Condition ( 1984 ) creates something he calls "paralogy" by lumping together quantum mechanics, Gödel's theorem, irreversible thermodynamics, and fractal geometry. In Lyotard's view, paralogy is a new kind of science that will "let us wage a war on totality" (p. 82). The common element in these very different theories, according to Lyotard, is their use of paradox to invalidate global concepts and valorize local knowledge. In chapter $8 \mathrm{I}$ argued that Lyotard's characterization of these theories is misguided, for they have not by any means abandoned globalizing concepts. Nevertheless, he is correct in positing a connection between the new scale-dependent scientific paradigms and the social matrix of postmodernism. This essential insight can be made more useful if we distinguish more carefully between different scientific sites and their various reinscriptions of postmodernism as a cultural dominant.

Consider how space is conceived in fractal geometry. As we have seen, fractal spaces are not Cartesian grids but complex forms characterized by multiple or infinite levels of self-similarity. One can imagine strolling through a city neighborhood along a grid of regularly spaced streets. We know very well how to orient ourselves in such spaces and consider them predictably well ordered. City space reproduces the Cartesian grid, just as the Cartesian grid replicates our experience of city space. By contrast, we do not know very well how to orient ourselves within the complex natural forms represented by mountains, clouds, and galaxies. The usual way people map such spaces is to impose Cartesian grids on them, such as the four compass points. Fractal geometry suggests a different method 
of orientation, for it sees these spaces as self-similar shapes generated through recursive iterations. Clearly this view does not correlate very well with the scale-invariant properties of city streets and Cartesian maps. What does it correlate with?

Think again of the Bonaventure's lobby-the four identical pillars that mock compass orientation by making it virtually impossible to tell one direction from another; the hanging streamers that convert the rectilinear volume into an irregular, constantly evolving shape. Think of Baudrillard's precession of simulacra, where there are only copies of copies in an endless display of self-similar forms, none of which can be privileged as more "original" than any other. Think of Gibson's cyberspace, in which people and computers become equally sentient entities vying for control of a space that is very real but entirely different from everyday life. I submit that the same forces that authorize these visions have also authorized fractal geometry. Fractal geometry is emerging as an important area of research because it is one way of conceptualizing and understanding postmodern space.

It is also becoming a source of this space. In a splendid example of the feedback loop between theory and culture, IBM recently sponsored a series of commercials featuring fractal geometry and Mandelbrot. Fractal geometry is also becoming a commodity in other ways. For example, Heinz-Otto Peitgen and P. H. Richter have used fractal images to market a handsome coffee-table book called The Beauty of Fractals (1986). Also available are fractal prints, fractal calendars, fractal T-shirts, and even fractal coffee mugs (which should of course be used on the coffee table with the book). Already a simulation, the computer-generated fractal image is thus transmuted into a series of simulacra in a process that Baudrillard would find predictable. In this regard, it is interesting to note that Mandelbrot has come in for criticism from other applied mathematicians, especially Michael Barnsley, for advocating that chance should continue to play a role in the generation of fractal images. ${ }^{10}$ In an essay revealingly titled "Making Dynamical Systems to Order," Barnsley argues that relying on chance makes fractals less useful for modeling

${ }^{10}$ Benoit B. Mandelbrot, "Fractals and the Rebirth of Iteration Theory," in Peitgen and Richter, I986:15I-I60; and Michael F. Barnsley, "Making Dynamical Systems to Order," in Barnsley and Demko, 1986:53-68. 


\section{Chaos Bound}

than using deterministic procedures that allow for greater control over the image (Barnsley and Demko, r 986:53-68). In view of how quickly fractal geometry has undergone commodification, the outcome of the debate is not difficult to foresee.

A similar correlation between culture and theory obtains between new scientific treatments of time. Time is rarely represented these days by pointers moving across a mechanical clock's face; instead it is signified by the blinking display of an electronic counter. Similarly, time in fractal geometry is not treated as the advancement of points along a number line. Rather, it is conceptualized as small changes in the iterative formulae that are used to generate fractal shapes. We saw in chapter 6 that small changes in these formulae result in large-scale changes in the fractal forms. Consequently, complex shape changes can be described in many fewer bits of information than would be required if one conceived of the shapes as masses of points that had to be advanced through time individually. Thus time still exists in fractal geometry, just as it does in cultural postmodernism. But it is no longer analogous to human movement through a Cartesian plane. Instead, it is envisioned in terms of what one needs to feed into the computer.

The close tie between computer technology and fractal geometry marks it as a site especially responsive to postmodernism as a cultural dominant. Mandelbrot and others have remarked that fractal geometry depends upon computers as no other geometry has done before it. It could equally well be said that computer use has developed in new ways because of fractal geometry. As we saw in chapter 6, computers have allowed mathematics to be practiced as an experimental science. When iterating fractal forms, for example, the computer operator does not need to know exactly what will happen. Instead she can feed in the initial values, watch the display, and adjust the variables accordingly as the display continues to change. Computer-generated fractals thus evolve in a continuous fluid interaction between human and machine intelligence. Global form and local inscription merge in this joining of human with computer.

Although I have chosen fractal geometry as an example, the same kinds of consideration apply to chaos theory generally. To show the relation between chaos theory and postmodernism, I will loop one more time through the narrative of postmodernism as I see it. In the 
early years of this century, efforts were made in a variety of areas to construct unified field theories that would eliminate ambiguity and self-reference. These efforts failed; but the failures brought to light certain intrinsic limits to representation. Having swung as far as it could in the direction of closure, the pendulum began to swing the other way as people became interested in exploring the implications of ungrounded representation. At the same time that global networks of communications, finances, energy sources, weapons research, and so forth made human lives on the planet more interdependent than they had ever been before, theoretical postmodernisms put forth urgent claims for fragmentation, discontinuities, and local differences. Cultural postmodernism arises from loops that build up between these seemingly divergent trends.

In its theoretical guises, cultural postmodernism champions the disruption of globalized forms and rationalized structures. In its technological guises, it continues to erect networks of increasing scope and power. Despite their apparent opposition, these two aspects of cultural postmodernism engage each other in self-sustaining feedback loops. Anxieties about the networks are expressed by theoretical postmodernisms; insofar as these expressions are acts of empowerment, however, they also relieve anxiety-and the networks continue to expand. It is the same paradox we saw in de Man, where the critique of mastery became so entwined with mastery that the two were inextricable. It is the same story told by new historicists, who narrate it even while it inscribes itself in the dialectic between them and their writing.

The science of chaos shares with other postmodernisms a deeply ingrained ambivalence toward totalizing structures. On the one hand, it celebrates the disorder that earlier scientists ignored or disdained, seeing turbulent flow not as an obstacle to scientific progress but as a great swirling river of information that rescues the world from sterile repetition. On the other hand, it also shows that when one focuses on the underlying recursive symmetries, the deep structures underlying chaos can be revealed and analytical solutions can sometimes be achieved. It is thus like other postmodernisms in that it both resists and contributes to globalizing structures.

It differs in its particular expression of this ambivalence. Chaos theorists do not perceive themselves as creating chaos, either 
through their discourse or through their representations. They believe that they merely recognize what was always there but not much noticed before. In other postmodernisms, it is not so clear that chaos inheres in the system rather than the theorist. In deconstruction, for example, the "always already" formula asserts that texts were always chaotic before anyone wrote about them, certainly before deconstruction appeared on the scene. But since texts were not generally perceived to be chaotic before deconstruction, the burden of proof is on the writer to show that it is not she who creates the chaos she reveals. This necessity leads to a certain amount of anxiety, for what the writer bestows the writer can take away. Deconstruction is therefore concerned that the disorder it celebrates and exposes can be undone if one is not unceasingly vigilant about how one writes and speaks.

I emphasize this difference between chaos theory and deconstruction because I believe that it is important to distinguish as carefully as possible between one site and another. The general patterns may be (recursively) the same, but the tonalities and precise dynamics of each site are unique. To speak of the sciences of chaos as postmodern science is not in my view to speak incorrectly. It is to speak carelessly, however, unless one specifies the tensions that mark a specific site and re-mark it with the distinctive dynamics that characterize it. Fractal geometry is not the same as nonlinear dynamics; nonlinear dynamics is not the same as information theory; information theory is not the same as thermodynamics. It goes without saying that greater differences distinguish any of these fields of inquiry from deconstruction and from the new historicism. While it is important to see that all postmodern theories have certain common characteristics that reinforce and are reinforced by the culture, it is also important to understand that different sites impart distinctive values to the ideas they share.

Having acknowledged the importance of local differences, I should like to make a global conjecture about why the sciences of chaos have been so energized by cultural postmodernism. Many scientists have commented that working on chaos has allowed them to renew their sense of wonder. ${ }^{11}$ Although they do not put it this way,

"This aspect of chaos theory is eloquently addressed in James Gleick's Chaos (1987). 
they intimate that chaos has given them a sense of being in touch with the Lacanian real. For them, chaos is an image for what can be touched but not grasped, felt but not seen. At a time when resistance to mastery is so sophisticated that it cannot help but be perceived as masterful, chaos presents them with a resistance that alleviates the fear of mastery. They see it as rescuing postmodernism from the prefix that positions us in "always already." They take chaos as demonstrating that there is something more than novelty, something other than the precession of simulacra. For them, chaos signifies the truly new. This is what they believe.

When chaos theory is located within the postmodern dialectic, however, a more complex picture emerges. As we saw in chapter 6, the same structures that have given us a gendered world also operate in the construction of chaos. The innocence of chaos is an assumption that is most tenable when one believes that the self is not itself constructed by the same forces that are replicated in theories and in the social matrix. When theory, self, and culture are caught in the postmodern loop, the construction of chaos cannot be unambiguous, because it derives from and feeds into the same forces that made us long for escape. Like all postmodern theories, chaos theory is marked by the ambivalence characteristic of this cultural moment.

\section{The Story of Chaos: Denaturing Narratives}

This, then, is the story of chaos and culture as I see it. It remains to say what status I wish to claim for my narrative. How can one write about postmodernism without being acutely aware that what one writes is itself a construction in the postmodern loop? For my part, I am conscious that out of the nearly infinite number of events that have happened in this century, I have chosen some few dozen to remark upon and weave together in a pattern. There can be no question that by choosing different locales, one could weave entirely different or contradictory patterns. Moreover, the assumptions informing my narrative are no doubt full of the very contradictions and ambivalences that I have described as characteristic of postmodernism. No, I have not described the social matrix. Even if my account were fuller and more complete than it is, I could not have achieved the vantage outside or above my culture which an "objective" de- 
scription would imply. At best I have reenacted the cultural dominant in such a way as to make its dynamics clearer than they may have been before. If my narrative is useful, it is because it self-consciously embraces what it cannot help being-a denatured construction.

Assuming that cultural history is always a dialogue between critics rather than an objective record of what happened, one would suppose that this dialogue changes over time, and that this evolution itself constitutes a narrative, or more properly a metanarrative. When Lyotard defined postmodernism in The Postmodern Condition as "incredulity toward metanarratives," he had in mind such specific social narratives as the story of scientific progress and the rise of democratic education (p. xxiv). But what are the essential components of narrative construction, if not language, context, time, and the human? The denaturing of experience, in other words, constitutes a cultural metanarrative; and its peculiar property is to imply incredulity not just toward other metanarratives but toward narrative as a form of representation. It thus implies its own deconstruction.

The denaturing of experience has important implications for narrative literature, especially narrative fiction. The denaturing process can be thought of as a set of vectors defining a textual field of play. The more vectors that are energized in a particular text or site, the more dimensional complexity the field will have, and consequently the more complicated it can be. In a fully denatured narrative, one would expect the language to be self-referential; the context to be self-consciously created, perhaps by the splicing together of disparate contexts; the narrative progression to be advanced through the evolution of underlying structures rather than through chronological time; and the characters to be constructed so as to expose their nature as constructions.

However, this list of literary strategies should not be construed as a set of criteria by which one can determine which narratives are "really" denatured or postmodern. Such a project would be selfcontradictory, for it presupposes that the criteria exist in an ideal reality removed from the phenomena they attempt to describe, whereas in fact they derive from a theory that is itself frankly a construction involved in a recursive loop with postmodern culture. 


\begin{abstract}
Although I have defined cultural postmodernism as the denaturing of experience and have placed it within the time frame of the twentieth century, the literary strategies mentioned above can be found in texts from virtually any period. What could be more self-referential than the end of A Midsummer Night's Dream, or more effective at representing the denatured human than Frankenstein? Postmodern texts do not have a monopoly on these literary strategies. It is not the literary strategies in isolation that make a text postmodern but rather their connection through complex feedback loops with postmodernism as a cultural dominant. Other times have had glimpses of what it would mean to live in a denatured world. But never before have such strong feedback loops among culture, theory, and technology brought it so close to being a reality.
\end{abstract}


